\title{
Reseña. 'A tomar por el culo'. Análisis interaccional de las identidades conversacionales y de la reorganización de roles en una charla sin monopolizadores del turno, por Alicia Sentí Janssen, 2018
}

\author{
LINCOM GmbH, 135 pp., 64,80 €, ISBN: 978-3862888894
}

Laura Acosta-Ortega

University of Oxford

Las investigaciones realizadas sobre conversación e interacción desde diferentes perspectivas, como el análisis de la conversación de Sacks, Jefferson y Schegloff (1974), la etnografía de la comunicación (Gumperz y Hymes, 1972) o el análisis del discurso, han permitido abrir un campo de estudio en el que se analizan los mecanismos que construyen la conversación en diferentes contextos. Gracias a dichos estudios pioneros conocemos cómo son las interacciones en diversas situaciones y cómo se comportan los hablantes de diferentes edades, estatus social, nivel de estudios, procedencia, etc. Entre las múltiples cuestiones analizadas en la interacción, se ha iniciado una línea de investigación que observa las diferencias en la gestión de la interacción entre hombres y mujeres en conversaciones coloquiales. De la misma manera que se ha estudiado cuáles son los estereotipos socialmente asociados a hombres y mujeres (Connell, 1995; Eckert, 2004); también en la conversación coloquial, investigaciones como la de Tannen (2005) o las de Acuña Ferreira $(2009,2015)$ apuntan algunos de los rasgos interactivos y discursivos que se han asociado prototípicamente a hombres y mujeres.

Este es el campo de estudio en el que se sitúa el trabajo de Alicia Sentí Janssen, que, con el sugerente título de 'A tomar por el culo'. Análisis interaccional de las identidades conversacionales y de la reorganización de roles en una charla sin 
monopolizadores del turno, analiza los comportamientos discursivos de los participantes en una charla entre un grupo de amigos, en concreto el papel conversacional de las mujeres en las interacciones mixtas y los recursos discursivos que emplean. El trabajo estudia, en definitiva, cómo incide la identidad de género en la gestión de los turnos de habla y en el rol que toman los hablantes en las interacciones.

El volumen recoge los resultados obtenidos por la investigadora en su Trabajo de Fin de Máster, realizado en el marco del Máster Interuniversitario en Lingüística Aplicada por las Universidades de A Coruña, Santiago y Vigo. Previamente al estudio que reseñamos, la autora realizó una investigación en la misma línea de trabajo (resultante de su Trabajo de Fin de Grado en Estudios de Galego e Español por la Universidad de Vigo), en la que se centró en la monopolización de la interacción llevada a cabo por los hombres participantes en una conversación entre amigos jóvenes. En el volumen, la autora compara los resultados obtenidos en la mencionada investigación previa, realizando de esta forma una historia conversacional (Golopentia-Eretescu, 1985), para observar los distintos estilos conversacionales de los mismos hablantes en situaciones comunicativas diferentes.

El volumen se estructura en los apartados clásicos de una investigación. Incluye una introducción, un breve marco conceptual, una explicación de la metodología empleada en la recogida y en el análisis de los datos, el análisis de los datos y unas breves conclusiones. El volumen se completa con las referencias bibliográficas mencionadas en el texto y la transcripción completa de los fragmentos analizados.

El cuerpo del análisis, a su vez, se divide en tres partes que se corresponden con tres fragmentos de interacción seleccionados entre los datos empíricos en los que se basa el estudio. Las secuencias han sido elegidas intencionalmente por la investigadora por ser fragmentos en los que las mujeres participantes en la interacción desarrollan un rol activo en la construcción del discurso. La selección de los fragmentos responde al objetivo de analizar cuáles son las estrategias discursivas que despliegan estas mujeres jóvenes e inferir cuáles son sus intenciones comunicativas y sus metas conversacionales. Cabe señalar que los tres fragmentos seleccionados se corresponden con secuencias narrativas. La primera secuencia se trata de un habla sobre terceros; en ella, los interlocutores cotillean sobre una persona no presente en la interacción. La segunda y la tercera secuencia objeto de estudio son narraciones de anécdotas personales. En una de esas secuencias se narra una experiencia de la infancia de una de las participantes, mientras que la tercera anécdota, 
contada conjuntamente, es una experiencia que han vivido varios de los participantes en la conversación.

El análisis realizado y presentado en el volumen es detallado y minucioso. En él se tienen en cuenta diferentes mecanismos discursivos, entre los que destacan aspectos interaccionales y pragmáticos. Así, se describe el grado de formalidad del léxico utilizado, la prosodia, quién toma el turno y de qué manera, entre otros. En el análisis, como hemos dicho, la autora se centra en cuestiones que están relacionadas con el género de los participantes y con sus identidades conversacionales en la interacción analizada, pero también analiza otros rasgos que se pueden atribuir al habla de los jóvenes en Galicia. En este sentido, destacamos el hecho de que, al haber recogido los datos en una sociedad bilingüe, se considere el cambio de código en el estudio y se explicite la explicación de algunos ejemplos al lector para que, en caso de no ser hablante de gallego, pueda seguir el análisis.

Recalcamos la detallada contextualización de cada fragmento analizado, con la explicitación de cuestiones que no están presentes en la interacción objeto de estudio (como menciones a fragmentos estudiados en investigaciones anteriores o a las referencias externas a las que el lector de las transcripciones no tiene acceso). Observamos, pues, que la investigadora hace un esfuerzo de transparencia en cuanto al acceso de los datos, su contextualización y la claridad en la explicación del análisis realizado, lo que aporta validez al estudio y a las conclusiones que presenta.

Contrasta esta transparencia en el análisis con algunos aspectos relacionados con la obtención de los datos, que la investigadora no especifica en el texto. Si bien se expone que los datos fueron obtenidos en una grabación oculta y que se ha cambiado el nombre de los participantes por cuestiones de privacidad, no se menciona si se ha pedido a esos participantes consentimiento informado, aspecto que toma especial relevancia desde una perspectiva ética de la investigación. Del mismo modo, durante la presentación de la metodología utilizada, no se especifica si la investigadora es una observadora-participante del evento comunicativo, hecho que solamente se menciona en las conclusiones del estudio. Consideramos que aclarar estos dos pequeños detalles facilitaría que quien lee pueda tener una visión completa de algunos aspectos éticos y de la recogida de los datos empíricos utilizados para el estudio.

En cuanto a las conclusiones del trabajo, la investigadora observa que, a diferencia de una investigación anterior, en la que los participantes masculinos monopolizaban los turnos de habla, las mujeres toman en esta interacción un papel 
no periférico, ocupando importantes roles en la narración de anécdotas. En este estudio, ante la ausencia de dichos participantes masculinos, las mujeres intervienen más y toman un rol central en la conversación, realizando un papel de narradoras principales en dos de las tres secuencias analizadas. En la secuencia en la que no toman un rol de narradoras principales, se muestran discutidoras con las opiniones vertidas por sus compañeros masculinos. Además, parecen recurrir a aspectos discursivos que tradicionalmente se han considerado "típicamente masculinos", como el uso del humor, de expresiones malsonantes, o de apelativos prototípicamente empleados por los hombres como "tío" o "macho", entre otros.

En el caso de los participantes masculinos de la conversación, la autora encuentra que uno de ellos mantiene un repertorio estilístico dispar, que va desde un estilo más masculino (interrumpiendo de forma poco conciliadora) en una de las secuencias analizadas, a un estilo más colaborativo en otras secuencias, en las que se esfuerza por colaborar y ofrecer apoyo. El otro participante masculino mantiene un rol menos interruptivo, caracterizado por intervenciones en las que busca demostrar su papel de conocimiento experto, lo que, según la autora, intenta mostrar una masculinidad intelectual que refuerza su estatus dentro del grupo.

Si bien a lo largo del análisis se menciona brevemente qué se ha considerado en estudios anteriores como rasgos "prototípicamente masculinos o femeninos", agradeceríamos que la autora contemplara en futuros estudios la exposición sucintamente en el marco conceptual de un resumen de los resultados más relevantes en cuanto a los rasgos conversacionales que se han clasificado en estudios previos como masculinos o femeninos, especialmente aquellos que se tendrán en cuenta en el análisis. La inclusión de este breve resumen facilitaría a quien lee poder partir de unas ideas previas que se completan o refutan en la investigación de Sentí Janssen.

Consideramos muy necesaria la futura línea de investigación que plantea la investigadora en sus conclusiones, en las que señala la necesidad de analizar si estamos superando el viejo concepto de estilo conversacional masculino o femenino, ya que, como apunta los resultados del análisis, la tendencia que predomina es la de un estilo transgresor o mixto. Señala la autora que quizás debamos tener en cuenta no tanto la identidad de género, como la riqueza estilística de los participantes y los matices identitarios que quieran expresar los hablantes en situaciones comunicativas diversas.

Para finalizar, felicitamos a la autora por el minucioso trabajo realizado y esperamos que siga investigando en este campo de estudio. Celebramos que se publiquen investigaciones en las que se analiza la gestión de la conversación y que 
ayuden a ampliar los conocimientos sobre la incidencia de la identidad de género en las interacciones cotidianas.

\section{REFERENCIAS}

Acuña Ferreira, A. V. (2009). Género y discurso: las mujeres y los hombres en la interacción conversacional. Múnich: Lincom Europa.

Acuña Ferreira, A. V. (2015). El lenguaje y el lugar de la mujer: sociolingüística feminista y valoración social del habla femenina. Tonos digital, 28, 1-30.

Connell, R. W. (1995). Masculinities. Cambridge: Polity Press.

Eckert, P. (2004). The good woman. En R. Lakoff (Ed.), Language and Woman's Place: Text and Commentaries (pp. 165-170). Oxford: Oxford University Press.

Golopentia-Eretescu, S. (1985). L'histoire conversationnelle. Documents de Travail et Prépublications (Centre International de Sémiotique et de Linguistique), 149, 1-21.

Gumperz, J. J., y Hymes, D. (Eds.) (1972). Directions in sociolinguistics: The ethnography of communication. New York: Holt, Rinehart, Winston.

Sacks, H., Jefferson, G., y Schegloff, E. (1974). A Simplest Systematics for the Organization of Turn-Taking for Conversation. Language, 50(4), 696. https://doi.org/10.2307/412243

Tannen, D. (2005). Conversational style: Analyzing talk among friends. Oxford: Oxford University Press.

\section{LAURA ACOSTA-ORTEGA}

Lectora de español en la Universidad de Oxford. Es doctora en Traducción y Ciencias del Lenguaje en la Universitat Pompeu Fabra, con una tesis sobre la competencia interaccional en español como lengua extranjera, bajo la dirección de la Dra. Carmen López Ferrero y la Dra. Maria Dolors Cañada. Sus líneas de investigación principales se centran la interacción oral en la enseñanzaaprendizaje de español como lengua extranjera y el análisis de la conversación.

laura.acosta-ortega@mod-langs.ox.ac.uk https://orcid.org/0000-0002-8065-8720

Acosta-Ortega, L. (2020). Reseña. 'A tomar por el culo'. Análisis interaccional de las identidades conversacionales y de la reorganización de roles en una charla sin monopolizadores del turno, por Alicia Sentí Janssen, 2018. Bellaterra Journal of Teaching \& Learning Language \& Literature, 13(2), e821. https://doi.org/10.5565/rev/jtl3.821 